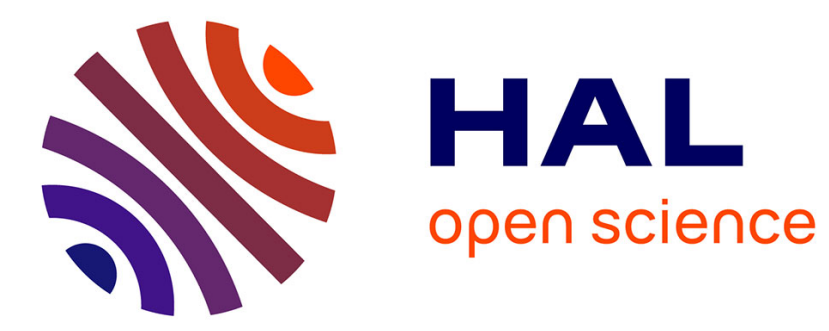

\title{
High-Pressure High-Temperature XAFS Investigation on $\mathrm{HgTe}$
}

Y. Katayama, M. Mezouar, J. Itié, J. Besson, G. Syfosse, P. Le Fèvre, A. Di

Cicco

\section{- To cite this version:}

Y. Katayama, M. Mezouar, J. Itié, J. Besson, G. Syfosse, et al.. High-Pressure High-Temperature XAFS Investigation on HgTe. Journal de Physique IV Proceedings, 1997, 7 (C2), pp.C2-1011-C2-1012. 10.1051/jp4:19972120 . jpa-00255179

\section{HAL Id: jpa-00255179 https://hal.science/jpa-00255179}

Submitted on 1 Jan 1997

HAL is a multi-disciplinary open access archive for the deposit and dissemination of scientific research documents, whether they are published or not. The documents may come from teaching and research institutions in France or abroad, or from public or private research centers.
L'archive ouverte pluridisciplinaire HAL, est destinée au dépôt et à la diffusion de documents scientifiques de niveau recherche, publiés ou non, émanant des établissements d'enseignement et de recherche français ou étrangers, des laboratoires publics ou privés. 


\title{
High-Pressure High-Temperature XAFS Investigation on HgTe
}

\author{
Y. Katayama ${ }^{(1)}$, M. Mezouar, J.P. Itié, J.M. Besson, G. Syfosse*, P. Le Fèvre** and A. Di Cicco*** \\ Physique des Milieux Condensés, Université Pierre et Marie Curie, BP. 77, 4 place Jussieu, \\ 75252 Paris cedex 05, France \\ * Département des Hautes Pressions, Université Pierre et Marie Curie, BP. 77, 4 place Jussieu, \\ 75252 Paris cedex 05, France \\ ** LURE and CEA, SRSIN, 91191 Gif-sur-Yvette cedex, France \\ *** Dipartimento di Matematica e Fisica, Universitá degli Studi di Camerino, \\ Via Madonna delle Carceri, 62032 Camerino (MC), Italy
}

\begin{abstract}
X-ray absorption measurenents at the $L_{3}$ edge of $\mathrm{Hg}$ it solid and liquid Hg'le have been perforned under high-temperature and high-pressure up to $1000 \mathrm{~K}$ and $3 \mathrm{GPa}$ using a large volume Paris-Edinburgh press. EXAFS spectra have been analyzed with GNXAS approach. The pressure dependencies of the nearest neighbor distance and the bond variance at room temperature as well as their variation with temperature at $0.6 \mathrm{GPa}$ have been obtained. The temperature dependence of the bond variance has been fitted to the Einstein model and is consistent to the decrease of the bulk modulus with increasing temperature, which has recently been shown to occur by an $x$-ray diffraction study.
\end{abstract}

\section{INTRODUCTION}

The pressure-temperature phase diagram and equation of state of HgTe have recently been precisely redetermined by $\mathrm{x}$-ray diffraction[1] $\mathrm{HgTe}$ has a zinc-blend structure at ambient pressure and it transforms to a cinnabar structure at $1.5 \mathrm{GPa}$ at $300 \mathrm{~K}$. The study revealed anomalous features of HgTe: (1) The bulk modulus, $B$, of zinc-blend phase decreases with increasing temperature. In addition, the magnitude of the temperature derivative of $B, d B / d T$, increases with increasing pressure. (2) The melting curve of the cinnabar phase is almost isothermal. Anomalies in liquid structure are expected under high pressure.

XAFS is a powerful tool to investigate local atomic structures for both solid and liquid phases. This method was successfully applied to high pressure studies, including crystalline $\mathrm{HgTe}$ [2]. It is also known that temperature dependence of EXAFS spectra gives information on vibrational properties. There are, however, very few XAFS studies under high pressure and high temperature conditions[3] mainly due to technical difficulties.

Recently a new type of large volume press, Paris-Edinburgh cell, has been developed for neutron diffraction experiments[4]. Its compactness enables us to install it in conventional XAFS beamlines. In this study we carried out $\mathrm{x}$-ray absorption measurements at the $L_{3}$ edge of $\mathrm{Hg}$ in solid and liquid $\mathrm{HgTe}$ up to $3 \mathrm{GPa}$ and $1000 \mathrm{~K}$ using this press.

\section{EXPERIMENTAL}

HgTe crystal was finely ground in a ball-milling and then mixed with fine BN powder in a weight ratio of 1:10. The high pressure chamber consists of two tungsten carbide opposed anvils which have conical hollows. The sample was put into a 2.0-mm-o.d., 1.5-mm-i.d. tube-type graphite heater, inside a gasket made of mixture of Boron and Epoxy. X-ray absorption measurements were performed by transmission method at W21 beamline at LURE. Synchrotron radiation from a superconducting wiggler device was monochromatized by a $\mathrm{Si}(111)$ double crystal monochromator. The beam was focused vertically by a mirror and horizontally by the 2nd crystal of the monochromator. The beam size was reduced to $0.5 \mathrm{~mm}$ in height and $1.0 \mathrm{~mm}$ in width by two slits. The $\mathrm{x}$-ray beam passed through the aperture between the two anvils. The intensities of incident and transmitted $x$-ray beams were monitored by an ionization chamber and a photo diode detector, respectively .

\section{RESULTS AND DISCUSSION}

EXAFS spectra of solid and liquid HgTe as a function of temperature and pressure have been analyzed using an ab-initio multiple-scattering data-analysis method (GNXAS) [5]. Data-analysis was performed taking into account double-electron excitation channels into the atomic background[6]. A reference $\mathrm{Hg} L_{3}$ EXAFS spectrum recorded at ambient pressure and temperature at the D42 beamline at LURE was used to test the accuracy of the model signal. Interatomic distance and bond variance were found to be $R=2.782 \AA$ and $\sigma^{2}=0.9 \times 10^{-2} \AA^{2}$. The $S_{0}^{2}$ amplitude factor associated was found to be $S_{0}^{2} \sim 0.84$ and kept fixed in the successive analysis of the high-pressure and hightemperature EXAFS spectra. The room-temperature high-pressure results up to $3 \mathrm{GPa}$ are in good agreement with an $x$-ray diffraction study[1] and an XAFS study in a diamond anvil cell[2].

(1) Present address: Department of Physics, Faculty of Science and Technology, Keio University, 3-14-1 Hiyoshi, Kohoku-ku, Yokohama 223, Japan 
In Fig. 1, the EXAFS spectra of HgTe at $0.6 \mathrm{GPa}$ are shown for increasing temperatures, from the bottom to the top. Solid $\mathrm{HgTe}$ was measured at $300,540,640$ and $760 \mathrm{~K}$, as indicated in Fig. 1. The first-neighbor Hg-Te twobody signal dominates the EXAFS spectra even at room temperature. The quality of the spectra decreases at high temperatures, and data at high wave-vector values were not considered at 640 and $760 \mathrm{~K}$. The coordination number was kept fixed to the known crystallographic value.

Figure 2 shows the variation of the bond variance, $\sigma^{2}$, as a function of temperature. The estimated error bars shown in the Fig. 2 are quite large due to poor signal-to-noise ratio. However, the trend of the temperature dependence can be still revealed. The dashed line indicates the result of a fit using the Einstein model[7]. The obtained $\omega_{\mathrm{E}}$ was $95 \mathrm{~cm}^{-1}$. It is in agreement with the optical phonon frequency measured at $0 \mathrm{GPa}, \omega_{\mathrm{TO}}=117 \mathrm{~cm}^{-1}$ and $\omega_{\mathrm{LO}}=135$ $\mathrm{cm}^{-1}[8]$. There is, however, discrepancy between the experimental points and the theoretical curve. To improve the fit we took the temperature dependence of the Einstein frequency into consideration. We estimated it from the temperature dependence of $B$, which was determined by a recent high-pressure x-ray diffraction study[1]. Actually the study revealed that $B$ decreased by $23 \%$ from $300 \mathrm{~K}$ to $800 \mathrm{~K}$ at $0.6 \mathrm{GPa}$. For cubic materials, a square-root law holds between Debye frequency, $\omega_{\mathrm{D}}$, and $B[9]$. We assumed that $\omega_{\mathrm{E}}$ has the same temperature dependence as $\omega_{\mathrm{D}}$. The solid line in the Fig. 2 shows the result of the fit. The agreement is better than with the simple model. The fitting parameter, $\omega_{\mathrm{E}}$ at $300 \mathrm{~K}$, is found to be $110 \mathrm{~cm}^{-1}$.

The EXAFS spectrum of liquid HgTe at $1000 \mathrm{~K}$ is shown on the top of Fig. 1. The only clear feature is the peak at about $4.5 \AA^{-1}$. The position and the height of this peak are sufficient to obtain an estimate of the Hg-Te mean distance and variance. A clear broadening of the first-neighbor distribution is then measured, although coordination number can float between 4 and 6 obtaining always reasonable fits. It is in agreement with the value, $6 \pm 0.8$, obtained by a recent neutron diffraction study on liquid $\mathrm{HgTe}$ at $0 \mathrm{GPa}[10]$. The bond length, $2.8 \pm 0.06 \AA$, has the same value than in the solid but is shorter than that determined by the neutron diffraction study.

This study shows that the XAFS experiments under high-pressure and high-temperature conditions using a large anvil cell are possible. They give unique structural and vibrational information which other methods cannot access under high-pressure high-temperature conditions.

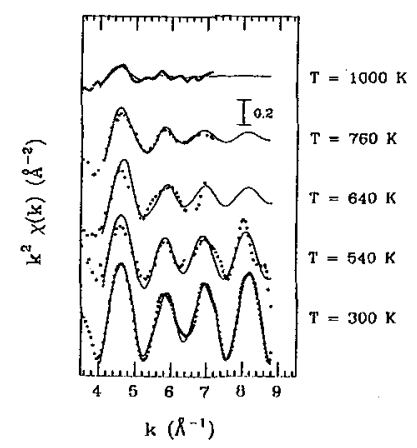

Figure 1: $\mathrm{Hg} L_{3}$-edge experimental (dots) and calculated(solid line) EXAFS spectra of solid and liquid $\mathrm{HgTe}$ at $0.6 \mathrm{GPa}$ as a function of temperature.

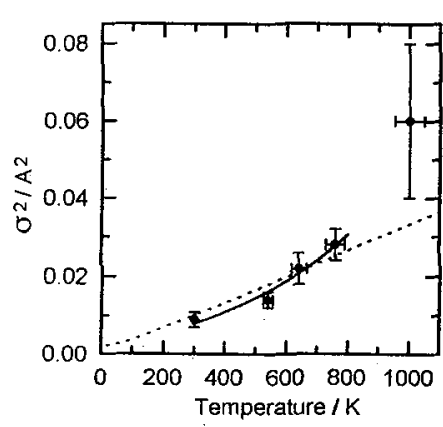

Figure 2: The temperature dependence of the bond variance for the first-neighbor distribution. The lines are the results of fits using Einstein model. See text for detail.

\section{Acknowledgments}

We would like to thank the LURE W21 staffs. We thank Dr. J. C. Tèdenac for giving us HgTe single crystals. This research has been partially financed by the TGE/CEE contract. One of us (YK) thanks Keio University for the financial support to the stay in Université P. et M. Curie.

\section{References}

* permanent address: Department of Physics, Keio University, 3-14-1 Hiyoshi, Yokohama 223, Japan.

[1] P. Grima, A. Polian, M. Gauthier, J. P. Itié, M. Mezouar, G. Weill, J. M. Besson, D. Häusermann and M. Hanfland, J. Phys. Chem. Solids 56, 525 (1995), P. Grima thesis (Université P. et M. Curie, 1995).

[2] A. San-Miguel, J. P. Itié and A. Polian, Physica B 208 \& 209, 506 (1995).

[3] Y.Katayama, K. Tsuji, O. Shimomura and H. Oyanagi, J. Non-Cryst. Solids, in print.

[4] J. M. Besson and R. J. Nelmes, Physica B 213\&214, 31 (1995).

[5] A. Filipponi, A. Di Cicco, T. A. Tyson, and C. R. Natoli, Solid State Commun. 78, 265 (1991); A. Filipponi, A. Di Cicco, and C. R. Natoli, Phys. Rev, B 152, 15122 (1995).

[6] A. Filipponi, L. Ottaviano, and T. A. Tyson, Phys. Rev. A 48, 2098 (1993).

[7] E. Sevillano, H. Meuth and J. J. Rehr, Phys. Rev. B 20, 4908 (1979).

[8] M. Grynberg, R. Le Toullec and M. Balkanski, Phys. Rev. B 9, 517 (1974).

[9] H. Siethoff and K.Ahlborn, phys. stat. sol. (b) 190, 179 (1995).

[10] J.-P. Gaspard J.-Y. Raty, R. Céolin and R. Bellisent, to be published in J. Non-Cryst. Solids. 